\title{
Growth Factor and Its Polymer Scaffold-Based Delivery System for Cartilage Tissue Engineering
}

This article was published in the following Dove Press journal:

International Journal of Nanomedicine

\author{
Li Chen ${ }^{1,2, *}$ \\ Jiaxin Liu ${ }^{\mathrm{l} *}$ \\ Ming Guan ${ }^{2,3}$ \\ Tongqing Zhou ${ }^{2}$ \\ Xin Duan' \\ Zhou Xiang'
}

'Department of Orthopedics, National Clinical Research Center for Geriatrics,

West China Hospital, Sichuan University,

Chengdu, Sichuan 61004I, People's

Republic of China; ${ }^{2}$ School of Dentistry,

University of Michigan, Ann Arbor, MI,

48109, USA; ${ }^{3}$ Department of

Orthopedics, Tongji Hospital, Tongji

Medical College, Huazhong University of

Science and Technology, Wuhan 430030,

People's Republic of China

*These authors contributed equally to this work
Correspondence: Xin Duan

Tel +86-28-85422426

Email dxbaal@hotmail.com

Zhou Xiang

Tel +86-28-85422605

Email xiangzhoul5@hotmail.com

\begin{abstract}
The development of biomaterials, stem cells and bioactive factors has led to cartilage tissue engineering becoming a promising tactic to repair cartilage defects. Various polymer three-dimensional scaffolds that provide an extracellular matrix (ECM) mimicking environment play an important role in promoting cartilage regeneration. In addition, numerous growth factors have been found in the regenerative process. However, it has been elucidated that the uncontrolled delivery of these factors cannot fully exert regenerative potential and can also elicit undesired side effects. Considering the complexity of the ECM, neither scaffolds nor growth factors can independently obtain successful outcomes in cartilage tissue engineering. Therefore, collectively, an appropriate combination of growth factors and scaffolds have great potential to promote cartilage repair effectively; this approach has become an area of considerable interest in recent investigations. Of late, an increasing trend was observed in cartilage tissue engineering towards this combination to develop a controlled delivery system that provides adequate physical support for neo-cartilage formation and also enables spatiotemporally delivery of growth factors to precisely and fully exert their chondrogenic potential. This review will discuss the role of polymer scaffolds and various growth factors involved in cartilage tissue engineering. Several growth factor delivery strategies based on the polymer scaffolds will also be discussed, with examples from recent studies highlighting the importance of spatiotemporal strategies for the controlled delivery of single or multiple growth factors in cartilage tissue engineering applications.
\end{abstract}

Keywords: polymer scaffold, growth factor, delivery, cartilage repair

\section{Introduction}

Articular cartilage is a specific type of connective tissue that covers the articular surfaces of the bone; it is mainly composed of a dense extracellular matrix (ECM) and a sparse cell population. ${ }^{1}$ It plays an essential role in the biomechanical functions of the joints, including shock absorption, sheer resistance and load bearing. ${ }^{2}$ Once articular cartilage is damaged, it has a limited potential for spontaneous repair due to the lack of vascularity, nerves and lymphatics. This can result in joint pain, swelling, dysfunction, and eventually lead to osteoarthritis (OA). ${ }^{3,4}$ In the past two decades, OA has been the most common form of arthritis accounting for approximately 300 million patients worldwide and undoubtedly has been considered as one of the most significant health problems that also pose a substantial financial burden on the public health system, and the patients themselves. ${ }^{5}$ Currently, conservative treatments, including pharmacological and non-pharmacological therapies, are commonly applied to improve joint pain, reduce stiffness and improve physical function in patients with OA. However, the therapies 
cannot prevent further joint degeneration. ${ }^{6}$ Surgical strategies are also designed to treat cartilage defects, including autologous chondrocyte implantation (ACI), microfracture, osteochondral grafts and total joint arthroplasty. However, they have some inherent shortcomings such as the requirement of secondary surgery, immunogenic responses, shortage of donor tissues and pathogen transmission risks. ${ }^{7-10}$ Alternatively, cartilage tissue engineering, which involves combining cells, scaffolds and growth factors, has emerged as a promising strategy for cartilage repair. ${ }^{11}$ Meanwhile, the methods of minimally invasive surgery, including the implantation and injection, are an important component of clinical translation of tissue engineering techniques which have been verified in vitro. ${ }^{12}$ In general, scaffolds as biologically active ECM provide mechanical support for cell growth and chondrogenic differentiation, which could be beneficial for stimulating and accelerating the cartilage regeneration process. With the development of chemistry and processing, numerous synthesized and natural materials have been applied to fabricate scaffolds that successfully promote the cartilage regeneration without noticeable signs of immune response and rejection. ${ }^{13-15}$

While biomimetic three-dimensional scaffolds have been made, they cannot create high-quality cartilage tissue independently. Stem cells, pluripotent cells and native progenitor cells are commonly used in combination with scaffolds to accelerate and improve the regeneration process. ${ }^{16,17}$ Moreover, cell-based therapies are influenced by the cellular microenvironment to some extent. Growth factors are of high importance as they have the potency to induce and enhance cellular responses, which is beneficial for the cells as they need to differentiate into desired lineages. ${ }^{18}$ Although scaffolds can obtain sufficient growth factors from the culture medium under in vitro conditions, the incorporated growth factors can spread out of the scaffolds and degrade in a short time in vivo. Besides, different dosages and delivery rates are required for different growth factors to induce the cells in in vitro or in vivo conditions. ${ }^{19,20}$ Today, a plethora of studies have been conducted to investigate the delivery of single or multiple growth factors from the scaffolds in a defined manner.

This review examined the delivery of growth factors for cartilage tissue engineering, with an emphasis on the polymer scaffold-based approaches. First, the aim is to enable an understanding of current applications of polymer scaffolds, following with the descriptions of different growth factors involved in cartilage tissue engineering. A latter section will place a particular emphasis on the growth factor delivery strategies associated with polymer scaffolds. Finally, the current challenges and suggestions of polymer scaffold-based growth factor delivery for cartilage tissue engineering are explained.

\section{Polymer Scaffolds}

Articular cartilage, with its unique mechanical properties provides the contact surfaces for load transfer between bones, which enables the joint to withstand weight-bearing. The ability to do so is attributed to its complex structure comprised of a fluid phase and a solid matrix that is composed mainly of a depth-dependent collagen fibrous network and proteoglycans, as well as other types of proteins, lipids, and cells. Therefore, the scaffold suitable for cartilage tissue engineering should have good biocompatibility for cell adhesion, migration and proliferation, and also provide appropriate mechanical and structural support. In addition, biodegradability and being free of adverse reactions are basic properties required for a three-dimensional scaffold mimicking physiological characteristics. ${ }^{21}$ Currently, a wide range of natural and synthetic polymers play an important role in the development of scaffolds for cartilage tissue engineering. Due to superior biocompatibility and biodegradation, natural polymers like collagen, chitosan, silk fibroin, alginate, hyaluronic acid and chondroitin sulfate are suitable for initiating a fast regeneration process. However, potential pathogen transmission, immunogenicity and poor mechanical properties limit their clinical application. ${ }^{22}$ On the other hand; synthesized polymers can artificially regulate the degree of polymerization, thereby controlling its mechanical properties, internal structure and degradation, which can effectively promote the regeneration process. Poly (lactic acid) (PLA), poly glycolic acid (PGA), poly lactide-co-glycolic acid (PLGA) and poly caprolactone (PCL) are the most commonly synthesized polymers in the application of three-dimensional scaffolds for cartilage tissue engineering. ${ }^{23}$ When comparing these to natural polymers, the properties of synthetic polymer-based scaffolds are considerably different in terms of their tunable properties, such as molecular weight, transition temperatures and crystallinity. ${ }^{24}$

Polymer nanofibers have been extensively studied due to their ability to encapsulate and deliver growth factors for different tissue regeneration purposes. Nanofiber scaffolds with high surface to volume ratio and interconnected porous structure, seem to hold the lead position as the ideal candidate for cartilage tissue engineering. ${ }^{25}$ They play a role in stimulating the ECM environment, allowing 
cells to populate empty spaces and organize themselves, and mechanical stimulation can be applied to this porous structure to orient the cells and maintain a chondrocyte phenotype. As a result, scaffolds will be degraded and replaced by newly formed ECM, without producing adverse effects due to the degradation products. To date, various technologies such as electrospinning, phase separation, self-assembly, drawing and template synthesis have been applied in attempts to optimize nanofiber scaffolds to make them more consistently bioactive and mechanically stable for effective tissue regeneration application. $^{26}$ For example; a nanofibrous scaffold was developed that was highly porous, interconnected and degradable. It was developed using phase separation of poly l-lactic acid (PLLA) solutions combined with porogen leaching techniques. Through a series of characteristic tests, chondrogenic evaluations in vitro and in vivo demonstrated that this nanofibrous PLLA scaffold is an excellent candidate providing an advantageous threedimensional microenvironment for a wide variety of cartilage repair strategies (Figure 1). ${ }^{27-29}$

\section{Growth Factors}

Growth factors are a group of peptides that mediate cellular proliferation, migration and differentiation by binding to transmembrane receptors located on target cells. When a sufficient number of receptors are activated, the signaling transduction process may trigger a series of specific cellular activities. ${ }^{30}$ Concerning cartilage development, growth factors play an essential role in regulating the processes of chondrogenesis and hypertrophy, such as the members of transforming growth factor- $\beta$ (TGF- $\beta$ ) superfamily, insulin-like growth factor-1 (IGF-1), fibroblast growth factor (FGF) family and platelet-derived growth factor (PDGF). In order to provide a better understanding of their potential, descriptions of their roles involved in the regeneration and maintenance of articular cartilage will now be described (Table 1).

\section{Transforming Growth Factor- $\beta$ Superfamily}

The TGF- $\beta$ superfamily is comprised of more than 30 closely related polypeptides, mainly including typical TGF- $\beta s$, bone morphogenetic proteins (BMPs), growth and differentiation factors (GDFs) and activin/inhibin, which regulate multiple cell functions from early development to regulating homeostasis throughout adult life. ${ }^{31}$
A large number of studies have shown that they have significant regulatory effects on the homeostasis and repair of articular cartilage.

\section{Transforming Growth Factor- $\beta$}

TGF- $\beta$ is a dimer with a molecular weight of 25 kilo Daltons $(\mathrm{kDa})$ that is composed of two identical or similar chains. There are three isoforms (1-3) that are generally considered to be potent stimulators in all stages of chondrogenesis with a function of inducing proteoglycans and type II collagen synthesis. ${ }^{32}$ TGF- $\beta$ signaling transduction is based on the membrane-bound heteromeric receptors (type I and type II). Binding to type II receptors leads to the phosphorylation of type I receptors, causing the phosphorylation of TGF- $\beta$ specific Smad proteins, particularly Smad 2 and $3 .{ }^{33}$ In addition, some Smad-independent pathways, including p38 mitogen-activated protein kinase (MAPK), extracellular signal-regulated kinase (Erk) and stress-activated protein kinase/c-Jun $\mathrm{NH}(2)$-terminal kinase $\left(\mathrm{SAPK} / \mathrm{JNK}\right.$ ) can also be activated by TGF- $\beta .^{34}$

TGF- $\beta$ is one of the main initiators of chondrogenesis of mesenchymal precursor cells, and the differentiation of mesenchymal stem cells (MSC) into chondrocytes also requires its stimulation. The expression of $\mathrm{N}$-cadherin was induced by strong stimulation of TGF- $\beta$ to enhance cell adhesion and aggregation, and subsequently promote cell proliferation, differentiation and deposition of the cartilagespecific extracellular matrix. ${ }^{35}$ Among these three isoforms, TGF- $\beta 1$ was the first to be discovered, and TGF- $\beta 1$ and TGF$\beta 3$ have been used in a large number of studies to explore the effect of TGF- $\beta$ on the repair of cartilage after it defects. Although some studies suggest that the ability of TGF- $\beta 2$ and TGF- $\beta 3$ to promote cartilage differentiation may be more superior to that of TGF- $\beta 1$, there is a consensus that there is no significant difference among the three TGF- $\beta$ isoforms regarding their ability to promote cartilage differentiation. ${ }^{36,37}$ In a Sprague-Dawley rat full-thickness cartilage defect model, Lentivirus-TGF- $\beta 1$-EGFP transduced BMSCs/calcium alginate gel significantly improved the amount of glycosaminoglycan (GAG) and type II collagen in the defect area in the early stage via activating the Smad pathway, when compared to a BMSCs/calcium alginate gel without TGF- $\beta 1$ transfection. Hypertrophy markers gene expression of chondrocytes were also inhibited by increasing Yes-associated protein-1 (YAP-1). ${ }^{38}$ Additionally, TGF$\beta 1$-incorporated collagen vitrigel had a better effect on managing the early pain mitigation and osteochondral defect repair compared to collagen vitrigel alone. ${ }^{39}$ Moreover, BMSC 

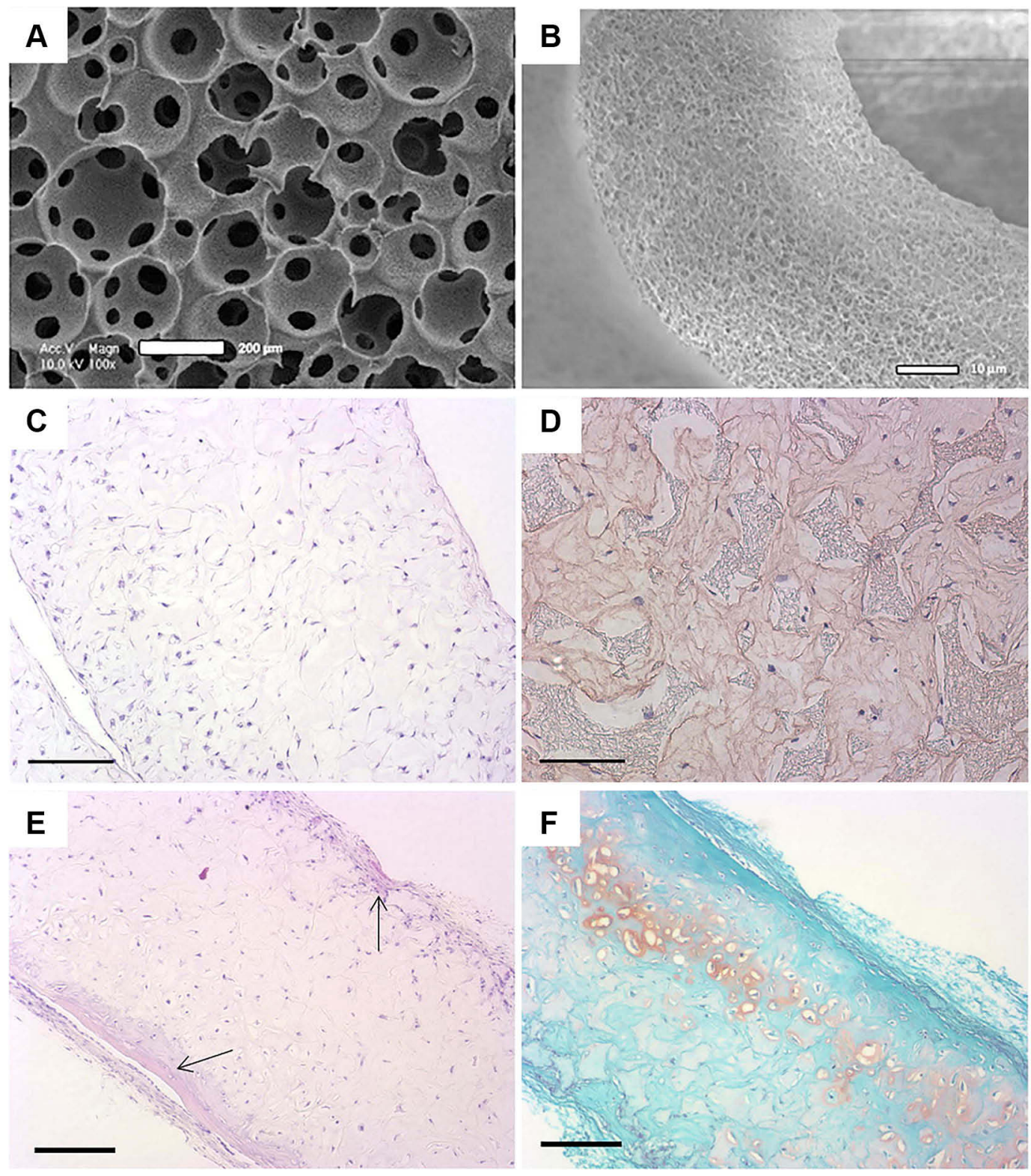

Figure I Nanofibrous PLLA scaffolds induce cartilage regeneration in vitro and in vivo. (A) SEM micrographs of nanofibrous PLLA scaffolds with macro-porous structures (Scale bar: $200 \mu \mathrm{m}$ ). (B) SEM micrographs of the nanofibrous microstructure of the pore walls at a higher magnification (Scale bar: $10 \mu \mathrm{m}$ ). (C) H\&E staining showed that BMSCs grew throughout the whole scaffolds after 4 weeks in vitro chondrogenic culture on nanofibrous PLLA scaffold (Scale bar: 200um). (D) Alcian blue staining showed a dense GAG matrix deposition after 4 weeks in vitro chondrogenic culture on nanofibrous PLLA scaffold (Scale bar: I00 $\mu \mathrm{m}$ ). (E) H\&E staining revealed that BMSCs/ nanofibrous PLLA scaffold constructs had typical cartilage morphology after 8 weeks implanted in nude mice (Scale bar: $200 \mu m$ ). (F) Safranin-O staining showed that BMSCs/nanofibrous PLLA scaffold constructs were positive for GAG-containing matrix in vivo (Scale bar: $200 \mu \mathrm{m}$ ).

Notes: Reprinted from Gupte MJ, Swanson WB, Hu J, et al. Pore size directs bone marrow stromal cell fate and tissue regeneration in nanofibrous macroporous scaffolds by mediating vascularization. Acta Biomater. 2018;82:I-II. Copyright (2018), with permission from Elsevier. ${ }^{27}$

were induced for the first 4 days with transient soluble TGF$\beta 1$, in which the accumulation of proteoglycans was 10 -fold higher than TGF- $\beta 1$-free culture after 3 weeks. These results suggest that TGF- $\beta$ promotes chondrogenic differentiation mainly depends on the extent of stimulation of the first week. ${ }^{40}$ Nevertheless, there are still some studies that do not support the role of TGF- $\beta$ in cartilage repair in vivo. In a rabbit osteochondral defect model, oligo polyethene glycol
(PEG) fumarate (OPF) hydrogel composites containing gelatin microparticles (GMPs) loaded with MSCs with or without TGF- $\beta 1$ did not improve cartilage morphology. ${ }^{41}$ Besides, undesirable side effects such as synovial fibrosis, endochondral ossification and hypertrophic scars were observed in vivo after a continuous stimulation by TGF- $\beta 1 .^{42-44}$ Therefore, it is crucial to properly deliver and present TGF$\beta s$ in vivo for cartilage regeneration. 
Table I Summary of the Representative Growth Factor Families Involved in the Cartilage Regeneration

\begin{tabular}{|l|l|l|l|}
\hline $\begin{array}{l}\text { Growth Factor } \\
\text { Family }\end{array}$ & Signal Pathway Involved & Regulatory Effects & References \\
\hline TGF- $\beta$ & $\begin{array}{l}\text { (a) Smad pathway: Smad 2 and 3 } \\
\text { (b) MAPK pathways: ERKs, JNKs and p38 } \\
\text { MAPK }\end{array}$ & $\begin{array}{l}\text { (a) Stimulates the proliferation and chondrogenic differentia- } \\
\text { tion of MSCs } \\
\text { (b) Improves ECM production } \\
\text { (c) Inhibits the degradation of cartilage }\end{array}$ & [33,34,38] \\
\hline BMP & $\begin{array}{l}\text { (a) Smad pathway: Smad I, 5 and 8 } \\
\text { (b) MAPK pathway: P38 MAPK }\end{array}$ & $\begin{array}{l}\text { (a) Induce the synthesis of ECM } \\
\text { (b) Promote the differentiation of MSCs }\end{array}$ & [45-48] \\
\hline IGF & $\begin{array}{l}\text { (a) PI3K-PKB pathway } \\
\text { (b) ERK I/2 pathway }\end{array}$ & $\begin{array}{l}\text { (a) Promote the proliferation of chondrocytes and MSCs } \\
\text { (b) Induce the synthesis of ECM } \\
\text { (c) Maintenance of cartilage phenotype }\end{array}$ & [55,57,58] \\
\hline FGF & $\begin{array}{l}\text { (a) STAT pathway: STAT I and 5 } \\
\text { (b) MAPK pathway: ERKs }\end{array}$ & $\begin{array}{l}\text { (a) Stimulates the proliferation of chondrocytes and MSCs } \\
\text { (b) Homeostasis of the cartilage matrix }\end{array}$ & [62,67] \\
\hline PDGF & (a) ERK I/2 pathway & $\begin{array}{l}\text { (a) Stimulates the proliferation of chondrocytes and MSCs } \\
\text { (c) Promoting the heterotopic cartilage formation }\end{array}$ & [68,69,72] \\
\hline
\end{tabular}

Abbreviations: TGF- $\beta$, transforming growth factor- $\beta$; BMP, bone morphogenetic protein; IGF, insulin-like growth factor; FGF, fibroblast growth factor; PDGF, plateletderived growth factor; MAPK, mitogen-activated protein kinase; ERK, extracellular signal regulated kinase; JNK, c-Jun N-terminal kinase; PI3K-PKB, phosphoinositide3-kinase-protein kinase B; STAT, signal transducers and activators of transcription; MSCs, mesenchymal stem cells; ECM, extracellular matrix.

\section{Bone Morphogenetic Protein}

BMPs are members of the TGF- $\beta$ superfamily. They have two active forms of homodimer and heterodimer, which can also induce differentiation of MSCs through the classical Smad and non-Smad pathways to form cartilage and promote the synthesis of cartilage $\mathrm{ECM}^{45}$ Studies have shown that blocking BMP activity can deplete proteoglycan, which in turn leads to a reduction in the intrinsic repair capacity of injured cartilage. Moreover, the congenital low regeneration capacity of articular cartilage was also found to be related to BMP antagonistic and catabolic cytokines. ${ }^{46,47}$ So far, at least 15 different BMPs have been found, of which BMP-2, BMP-4, BMP-6 and BMP-7 have been the most widely studied in the field of cartilage tissue engineering. ${ }^{48}$ Particularly, BMP-2 has been proven to be highly expressed throughout the chondrogenic process; thus, it has been commonly applied to improve cartilage regeneration in vitro and in vivo. ${ }^{49}$ Furthermore, in a rabbit articular cartilage defect model, combined therapy of microfracture and long-term BMP-2 delivery showed an advantage in the regeneration of hyaline-like cartilage, compared to microfracture with a short-term BMP-2 delivery. ${ }^{50}$ At present, there is still controversy surrounding the ability of different isoforms of BMPs to induce cartilage regeneration. Sekiya et al demonstrated that the ability of BMP-2 to promote chondrogenic differentiation of bone marrow-derived MSCs is more potent than that of BMP-4 and BMP- 6 based on the quantification of proteoglycans and type II collagen, as well as the size and weight of the cartilage that is being synthesized. ${ }^{51}$ However, another study reported that BMP-2 contributed to a better restoration of subchondral bone in contrast to the superior efficacy of BMP-4 for hyaline cartilage repair. ${ }^{52}$ Although there are a large amount of studies supporting BMPs in their ability to promote chondrogenic differentiation of MSCs alone or synergistically with other factors such as TGF- $\beta$, most BMPs can also induce osteogenesis. In addition, heterotopic ossification induced by BMPs is an important issue that needs to be further studied and overcome, especially in the joint cavity. ${ }^{53,54}$

\section{Insulin-Like Growth Factor}

In in vitro and in vivo studies, both insulin-like growth factor (IGF) isoforms, IGF-1 and IGF-2 have been shown to promote the proliferation of chondrocytes, stimulate the synthesis of the extracellular matrix of cartilage, and inhibit the activity of extracellular matrix-degrading enzymes, which is beneficial to the cartilage repair. ${ }^{55,56}$ Especially, IGF-1 was shown to induce chondrogenic differentiation of MSCs independently, and its functions were enhanced when combined with other growth factors. ${ }^{57,58}$ Gugjoo et al reported that IGF- 1 and TGF- $\beta 1$ into laminin gel 
scaffold in conjunction with allogeneic bone marrow mesenchymal stem cells (BM-MSCs) obtained a better effect on hyaline-cartilage formation with an improved cellular arrangement compared to laminin gel scaffold loading IGF-1 alone in rabbit osteochondral defects. ${ }^{59}$ In addition, IGF-1 and BMP-2 transfected rabbit adiposederived stem cells (ADSCs) resulted in higher production of type II collagen with reduced production of matrix metalloproteinase-3 (MMP-3). ${ }^{57}$ Interestingly, similar synergistic effects of IGF-1 combined with BMP-2 on cartilage regeneration are not always consistent in vivo. The dual delivery of IGF-1 and BMP-2 based on the macromere OPF appeared to have a synergistic effect on improving subchondral bone formation rather than promoting hyaline cartilage formation in a rabbit osteochondral defect model, at 12 weeks post-implantation. ${ }^{60}$ Similarly, an IGF-1 treated rabbit osteochondral defect exhibited good results for cartilage repair and morphology; however, the benefits were not maintained when TGF- $\beta 1$ was added. ${ }^{61}$ Based on these controversies, IGF-1 in conjunction with other growth factors for cartilage repair in vivo and the optimal delivery strategy remains to be fully elucidated in the future.

\section{Fibroblastic Growth Factor}

The fibroblast growth factors (FGFs) are a family of 22 highly homologous polypeptides which have been shown to have the potential for promoting tissue regeneration. Concerning cartilage, FGFs are closely related to chondrocyte proliferation, joint development, and homeostasis of the cartilage matrix. Basic FGF (bFGF) or FGF-2 is the representative member that has been the most examined in terms of the effect on chondrocytes and MSC. FGF-2 treatment affected maintaining the chondrogenesis potential during monolayer cartilage expansion through changing the structure of F-actin elements and allowing for more effective use of harvested tissue for cartilage regeneration. ${ }^{62}$ In an in vitro setting, SOX9 was upregulated in FGF-2 exposed human MSCs (hMSCs) leading to early chondrogenic differentiation by a priming mechanism. ${ }^{63,64}$ Besides, FGF-2-incorporating fibrin clot treatment proved to be useful for the regenerative repair of articular cartilage as well as for the underlying subchondral bone. ${ }^{65}$ However, the combination of FGF-2 and BMP-6 could suppress the ability of the latter to induce chondrogenic differentiation. ${ }^{66}$ There is also research reporting that FGF-2 can inhibit TGF- $\beta$ and weaken the chondrogenic potential of TGF- $\beta$ in mouse-derived
MSCs. ${ }^{67}$ However, FGF is involved in cartilage development, and the process of chondrogenic differentiation of MSCs and its interaction with other growth factors remains to be further studied in order to clarify the optimal strategy for cartilage regeneration in vitro and in vivo.

\section{Platelet-Derived Growth Factor}

Reports have shown that platelet-derived growth factor (PDGF) has potent mitogenic and chemotactic effects on cells of mesenchymal origin, including MSCs and chondrocytes. Prolonged exposure to PDGF-BB, chondrocytes were observed to be significantly increased in a dose-dependent manner as well as enhancing the cartilage matrix production, while suppressing the progression of cells along the endochondral maturation pathway. ${ }^{68}$ In addition, PDGF, in conjunction with high-pressure oxygen, can significantly enhance hyaline cartilage regeneration in the site of cartilage defects in a rabbit model. ${ }^{69}$ Sarban et al assessed the potential use and histological effects of the local administration of PDGF for full-thickness osteochondral defects; macroscopic and histological improvement was harvested. ${ }^{70}$ G-proteincoupled receptor kinase interacting protein-1 (GIT1), a protein in relation with focal adhesions, cell growth and migration, was recently shown to be upregulated by PDGF and subsequently resulted in promoting chondrocyte proliferation and migration. ${ }^{71}$ However, the addition of PDGF to human chondrocytes led to the expression of dedifferentiation related genes being stimulated. ${ }^{72}$ A similar phenomenon also occurred in human chondrocytes that were treated with human platelet supernatant, which is a rich source of PDGF. ${ }^{73}$ Accordingly, dosing requirements and optimum exposure rates need to be further evaluated to derive a clear benefit of this approach in cartilage tissue engineering.

\section{Scaffold-Based Growth Factor Delivery}

For decades, a wide variety of scaffolds seeded with cells have been developed to promote cartilage regeneration in a specific medium containing various growth factors. Although these constructs have achieved some success in vitro, regulatory approval and clinical transformation have been complicated due to manufacturing variability. ${ }^{74}$ In addition, growth factors can only exert their best potential at the site of injury; however, it is difficult for them to remain active after reaching the extracellular matrix since they are easily inactivated under physiological conditions. Generally, cartilage tissue engineering-related growth 
factors such as TGF- $\beta$ s and BMPs have a short half-life, especially in vivo; thus a single dose of growth factor is not sufficient to initiate cartilage formation, and the supraphysiological dose is often required to have a specific effect on the treatment of cartilage defects. Scaffoldbased growth factor delivery systems that mimic the natural cartilage healing process are more likely to achieve functional neocartilage tissue formation. To date, various strategies have been developed to enable spatiotemporal control over the growth factor from the scaffold.

\section{Surface Presentation Non-Covalent Incorporation}

Three-dimensional matrices and porous scaffolds, due to their intrinsic physical and chemical properties, have been widely used to deliver bioactive factors through creating concentration gradients by diffusion of the factors around the injury site. One of the most common approaches for scaffold-based delivery is the simple dispersion of growth factors in the matrix. This approach preserves the superior properties of the scaffold and does not destroy the biological activity of the growth factor. However, the growth factor release profile is inherently influenced by the interaction between the matrix and factor though either electrostatic interactions, ECM affinity, or hydrophobic interactions. $^{75-77}$ Recently, in order to improve the scaffold affinity for growth factors, the surface coating has been commonly exploited. Proteins such as gelatin, fibronectin and heparin can be physically and chemically coated to enable specific biological sites to immobilize the growth factors. ${ }^{35,78,79}$ In a rabbit cartilage defect model, human fibroblast-derived matrix (hFDM) -coatedPLGA/PLLA microfiber scaffold loaded with TGF- $\beta 1$ proved to be the most effective in forming neo-cartilage, compared to treatments without TGF- $\beta 1$. Based on the electrostatic interaction of TGF- $\beta 1$ with heparin, hFDM +heparin microfiber scaffolds had a higher TGF- $\beta 1$ loading capacity, and a sustained release of TGF- $\beta 1$ for up to 28 days was observed, as compared to the hFDM-minusheparin microfiber scaffolds that exhibited a notably higher initial burst release in the first 7 days. ${ }^{35}$ Similarly, Chen and colleagues demonstrated that silk fibroin-coated porous gelatin scaffold released significantly less SDF-1 $\alpha$ and TGF- $\beta 1$ than non-coated porous gelatin scaffolds over 2 weeks. ${ }^{80}$ While there are some certain preferred features, physical absorption has limited potential to enable a predictable long-term sustained delivery system. In addition, environmental conditions such as temperature, acidity and hydrophobicity, could also affect the release kinetics and effectiveness of growth factors presented by surface physical absorption.

\section{Covalent Incorporation}

Covalent bonding of growth factors to scaffolds has been seen to have an advantage in the management of prolongedrelease systems compared to the physical absorption method. The incorporation is based on the copolymerization or chemical or physical reactions of functional groups between scaffolds and factors. ${ }^{81}$ For example, the amine group of TGF- $\beta 3$ and the carboxyl group of PLGA/gelatin/ chondroitin sulfate/HA scaffolds were crosslinked for immobilization, which allowed TGF- $\beta 3$ to exhibit a sustained released over 28 days. Moreover, the chondrogenic differentiation of MSCs on a TGF- $\beta 3$ immobilized scaffold achieved a similar level compared to nonimmobilized scaffolds that were cultured in chondrogenic differentiation medium supplemented with TGF- $\beta 3 .{ }^{82}$ However, many scaffolds involved in cartilage tissue engineering are degradable and lack reactive functional groups. Therefore, it is necessary to optimally activate the scaffolds while maintaining their integrity. Post-fabrication modification and bending with growth factors before fabrication is the main approaches for functionalization. One primary concern in this process is that a chemical reaction may change the molecular structure of the growth factor and thereby result in a loss of bioactivity. ${ }^{83}$ Growth factor peptide mimics are promising to enable growth factor release from scaffolds to display their optimal and genuine functions. For instance, TGF- $\beta 1$ mimicking peptide, cytomodulin-10 (CM10) was conjugated onto the PLLA-based functional nanofibrous hollow microspheres (FNF-HMS) and then evaluated for promoting cartilage formation. The results indicated that the developed FNF-HMS, compared to the non-modified scaffold, effectively presented CM10 to rabbit BMSCs and significantly promoted their chondrogenic differentiation for cartilage formation in the nude mice after subcutaneous injection (Figure 2). ${ }^{84}$

\section{Encapsulation and Pre-Programmed Delivery Physical Encapsulation}

Due to its simplicity, physical encapsulation of growth factors within the scaffolds is an appealing alternative to protect factors from premature degradation, as well as reducing side effects on the non-targeted tissues. To date, various fabrication techniques for physical encapsulation 


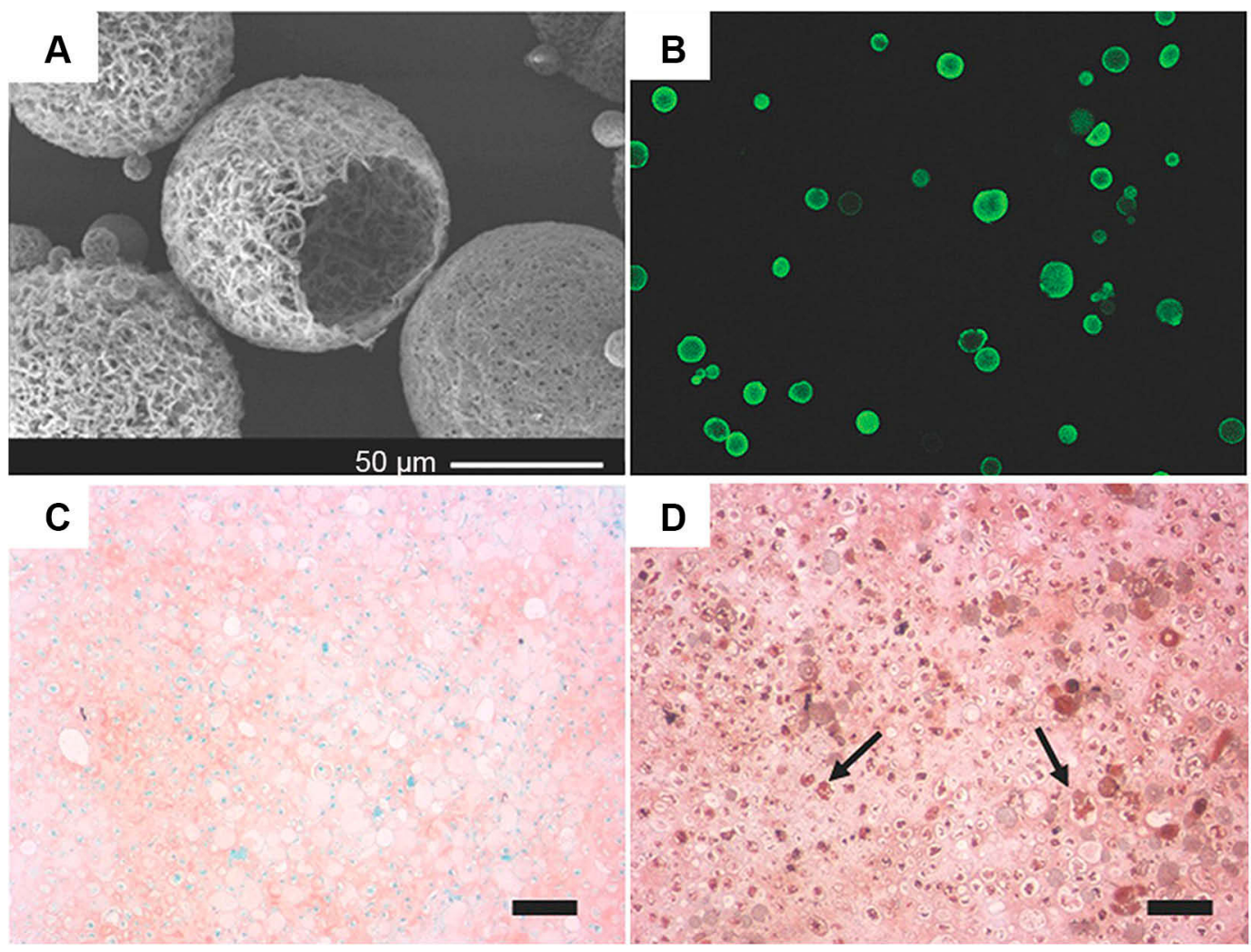

Figure 2 TGF- $\beta$ I mimicking peptide with surface modified nanofibrous PLLA microspheres induced stem cell chondrogenesis. (A) SEM images of surface modified nanofibrous microspheres. (B) A cross-sectional confocal image of FNF-HMS after fluorescent tagging of the conjugation sites. (C) Positive safranin-O staining for GAG in CMI0-FNF-HMS/BMSCs group after 2 weeks subcutaneous implantation. (D) Positive immunohistochemical staining for collagen type II in CMO-FNF-HMS/BMSCs group after 2 weeks subcutaneous implantation. Scale bar: $100 \mu \mathrm{m}$.

Notes: Reprinted from Zhang Z, Gupte MJ, Jin X, Ma PX. Injectable Peptide Decorated Functional Nanofibrous Hollow Microspheres to Direct Stem Cell Differentiation and Tissue Regeneration. Adv Funct Mater. 20I5;25(3):350-360. Copyright 2015 with permission from John Wiley and Sons. ${ }^{84}$

have been developed that include freeze-drying, phase emulsion, phase separation, solvent casting and particulate leaching, gas foaming and in situ polymerization. ${ }^{79}$ The major challenge with this strategy is to minimize the growth factor exposure to hazardous solvents that is common in the scaffold fabrication process. Gas foaming seems to provide an alternative approach to avoiding inactivation of growth factors as the process is free of solvents, and the delivery of growth factors can be obtained with these scaffolds. To a large extent, the final structure of the scaffold depends on the choice of polymer material and gas. ${ }^{85}$ Carbon dioxide $(\mathrm{CO} 2)$ has been identified to be a promising choice to create porous polymer scaffold structures and can also lead to an expansion of the scaffold matrix, facilitating growth factor encapsulation. ${ }^{86}$ A general drawback of physical encapsulations should be noted as it is difficult to control the release kinetics of growth factors, and an initial burst release is common. ${ }^{87}$ Recently, liposomes have become a promising approach to encapsulate hydrophilic growth factors due to their high loading efficiency, tolerance and tunability. Besides, liposome-based growth factor delivery systems avoid the use of harsh organic solvents during preparation and can, therefore, potentially enhance biocompatibility. They can also be easily functionalized for enhanced retention, and targeting. ${ }^{88}$ Filova et al developed a cell-free hyaluronate/ type I collagen/fibrin composite scaffold containing polyvinyl alcohol (PVA) nanofibers. After taking advantage of enriching liposomes encapsulating bFGF and insulin, a time-controlled release of these two factors was observed; and successful stimulation for the cartilage regeneration was seen in vitro and in vivo. ${ }^{89}$ However, liposome-based delivery systems are also reported to be unstable in physiological environments, which results in a relatively short duration of release profile. ${ }^{90}$

\section{Microparticles}

Microparticles (MPs) act as an excellent carrier for bioactive factor encapsulation due to some crucial properties such as a high surface area to volume ratio, small dimensions, high 
loading efficiency and high diffusibility ${ }^{91,92}$ Once the MPs that encapsulate growth factors are in contact with the water environment; water molecules enter the interior of the MPs, which makes the MPs swell. The diffusion channels generated by this swelling process allow the growth factors to diffuse into the external environment. At the same time, the growth factors are released with the degradation of MPs. ${ }^{93}$ The release rate can be regulated, including the molecular size and loading amount of the growth factor, the composition and relative molecular mass of the polymer, and the size and shape of the MPs. ${ }^{94}$ When growth factor loaded MPs immobilize onto the scaffolds, they can show an advantage in controlling release kinetics of single or multiple growth factors spatially and temporally without altering the scaffold structure. ${ }^{95}$ Numerous natural polymers, including gelatin, collagen, chitosan, hyaluronic acid, alginate and silk, have good biocompatibility, and so have been widely applied to fabricate MPs delivering growth factors for cartilage tissue engineering. ${ }^{96-100}$ Gelatin, a representative natural material derived from collagen type I, is an example that has successfully been used to incorporate TGF- $\beta 1$ for enhancing the chondrogenic differentiation of human periosteum derived cells. Moreover, for positively charged growth factors, acid gelatin MPs show a strong affinity, which has been reported for controlled delivery of BMP-2, TGF- $\beta 1$ and TGF- $\beta 3$ in cartilage tissue engineering. ${ }^{92}$ However, a potential issue in the application of natural polymers for MPs is that the degradation rate is challenging to control as well as them having a relatively short release period; which then requires additional chemical modification. In addition to natural polymers, synthetic polymer-based MPs have traditionally been growth factor delivery vehicles for several decades. In this context, PLGA, a member of the US Food and Drug Administration (FDA) approved biodegradable polymers, has become the most commonly used synthetic polymer for MP application because of its potential for desired bioactive factor delivery relevant parameters can be tuned, such as the ratio of lactide to glycolide and polymer molecular weight. ${ }^{101}$ TGF- $\beta 1$ loaded PLGA MPs have been immobilized onto the collagen/silk fibroin composite scaffold, which was evaluated in entirely thick articular cartilage defects in rabbits. Compared to the collagen/silk fibroin composite group, TGF- $\beta 1$ was released from the scaffold and incorporated into MPs in a sustained fashion while having a significant effect on the forming of neocartilage within the scaffold (Figure 3). ${ }^{102}$ However, when PLGA microspheres that encapsulated TGF- $\beta 1$ they were incorporated into the PEGbased scaffold, and the initial release of TGF- $\beta 1$ was notably decreased and presented a control sustained release kinetic profile with high bioactivity. ${ }^{103}$ While synthetic polymerbased MPs have the advantage of achieving release kinetics in a defined manner, they also face the potential issue that the degradation products may cause an inflammatory tissue response as well as affecting the bioactivity of growth factors. The ideal MP/three-dimensional scaffold system requires the selection of MP and scaffold materials according to the requirements of the regenerated tissue. Moreover, it is vital to reasonably combine the growth factors, MPs and scaffolds to achieve spatial and temporal patterns of growth factor delivery.

\section{Nanoparticles}

Nanoparticles (NPs) are another promising delivery vehicle that are attracting interest in cartilage tissue engineering. Compared to MPs, NP growth factor delivery systems exhibit a similar release mechanism, while they have higher versatility as NPs can release growth factors outside and inside of target cells. They show good performance in their affinity to growth factors, allowing for the accumulation of encapsulated growth factors due to them having a greater surface area to volume ratio. ${ }^{104}$ Polymeric NPs play an essential role in growth factor encapsulation as they have better bioavailability, distribution and pharmacokinetic profiles. ${ }^{105}$ Recently, Kim et al developed fibrous PLGA scaffold integrated with BMP-7 loaded PLGA NPs, and subsequently combined them with synovial-derived MSCs to test the effect on full-thickness osteochondral defects in rabbits. The results demonstrated that BMP-7, through a control sustained release fashion, effectively enhanced the chondrogenic potential of synovial-derived MSCs contributing to high collagen type II and proteoglycan production and thick hyaline cartilage formation (Figure 4). ${ }^{106}$ In another study, chondroitin sulphate NPs containing TGF- $\beta$ were added to the chitin and poly caprolactone scaffold, whereby a prolonged release of TGF- $\beta$ over 4 weeks was observed which ultimately improved the attachment, proliferation and chondrogenic differentiation of rabbit adipose-derived stem cells. ${ }^{107}$ Although NPs show many advantages in the field of growth factor delivery; their intrinsic properties also bring challenges to technological development. Furthermore, a high surface area to volume ratio increases the NPs loading efficiency of growth factors, while it may reduce the stability of the NPs during the preparation process such that their advantages could be decreased. 

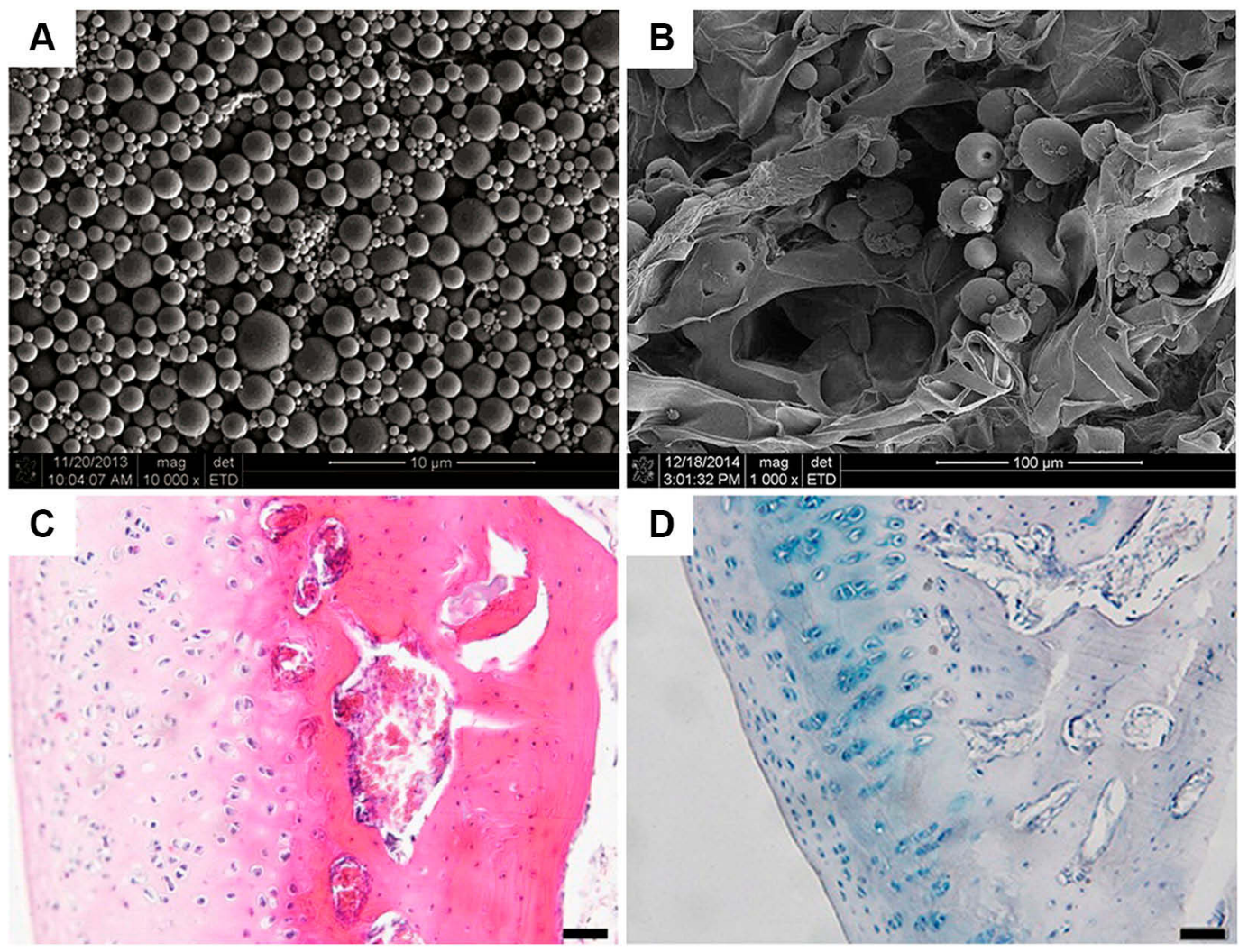

Figure 3 Collagen/silk fibroin composite scaffold incorporated with TGF- $\beta$ I loaded PLGA microspheres for cartilage repair. (A) SEM image of TGF- $\beta$ I loaded PLGA microsphere. (B) SEM image of composite scaffold incorporated with PLGA microspheres. (C) H\&E staining showed a well-developed regenerated hyaline articular cartilage in the group of composited scaffolds with TGF- $\beta$ I loaded PLGA microspheres. (D) By Alcian blue staining, an abundance of cartilage matrices that were found in the group of composited scaffolds with TGF- $\beta$ I loaded PLGA microspheres. Scale bar: $50 \mu \mathrm{m}$.

Notes: Reprinted from Wang J, Yang Q, Cheng N, et al. Collagen/silk fibroin composite scaffold incorporated with PLGA microsphere for cartilage repair. Mater Sci Eng C Mater Biol Appl. 2016;61:705-71।. Copyright (2016), with permission from Elsevier. ${ }^{102}$

\section{Layer by Layer Assembly}

Layer-by-layer (LBL) assembly is a gentle, bottom-up and straightforward nanofabrication technique to make polyelectrolyte multilayers. It has been commonly used to modify porous scaffolds with a flexible structure for controlled delivery of growth factors, as it shows good performance in avoiding growth factors loss of function and sequestering the high concentration of growth factors under mild aqueous conditions. ${ }^{108}$ For this assembly process, typical hydrogen bonding, covalent interactions or electrostatic interactions are commonly used. By assembling alternating layers of sodium poly styrene sulfonate (PSS) and poly allylamine (PAH) onto planar surfaces, the polymeric multilayer capsules store growth factors and maintain their biological activity. ${ }^{109}$ In addition, dextran sulphate and heparin were chosen to be the counter polyelectrolytes in order to better protect growth factor ligands. ${ }^{108}$ The morphology of the film prepared by LBL assembly is controllable and can also be compounded with other carriers. During the process, through adjusting the inherent properties of the polyelectrolyte multilayers, the growth factor release behavior can be regulated. As a result, the desired control release and high loading capacity could be obtained through a highly optimized LBL assembly process. ${ }^{110}$ Three-dimensional bioprinting presents as a novel LBL process that can integrate the materials with growth factors to construct a three-dimensional scaffold. Thus, showing potential in the context of controlled delivery. It is interesting to note that the ability of three-dimensional bioprinting of spatially patterned different growth factors can generate concentration gradients of these factors to mimic the complex development of different natural tissues. ${ }^{111}$ Through water-based three-dimensional bio-printing, the water dispersion of polyurethane (PU), hyaluronan (HA) and TGF- $\beta 3$ were integrated to construct compliant scaffolds. TGF- $\beta 3$ was conveniently embedded and released from the scaffolds in a prolonged manner; it subsequently led to significant upregulation of the chondrogenic related genes expression level, including SOX9, ACAN and COL2A1, which suggests an advantage of threedimensional bioprinting may be an alternative for developing 
A

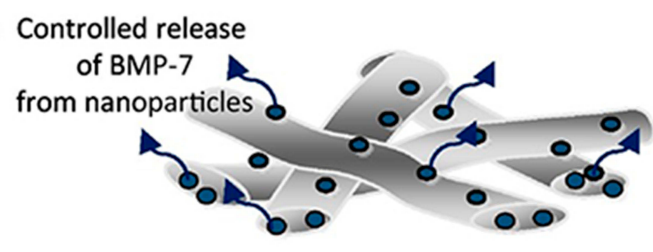

Fibrous PLGA scaffolds

C

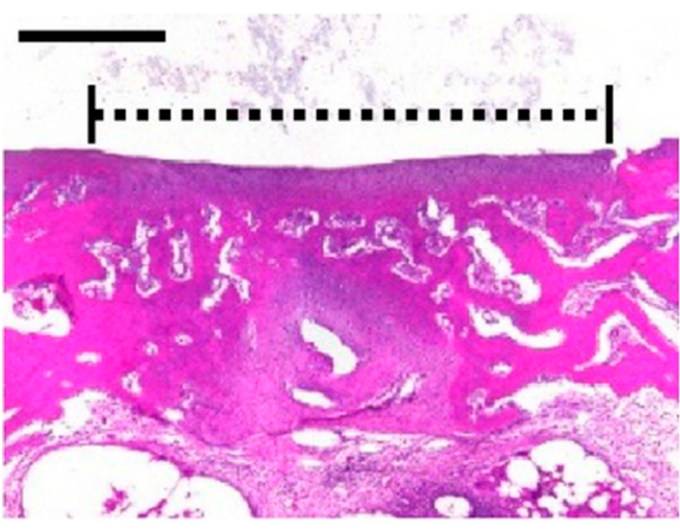

$(40 x)$
B

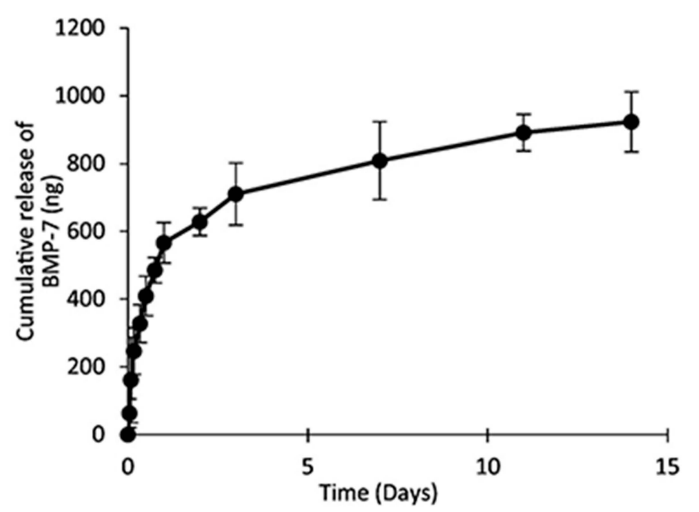

D

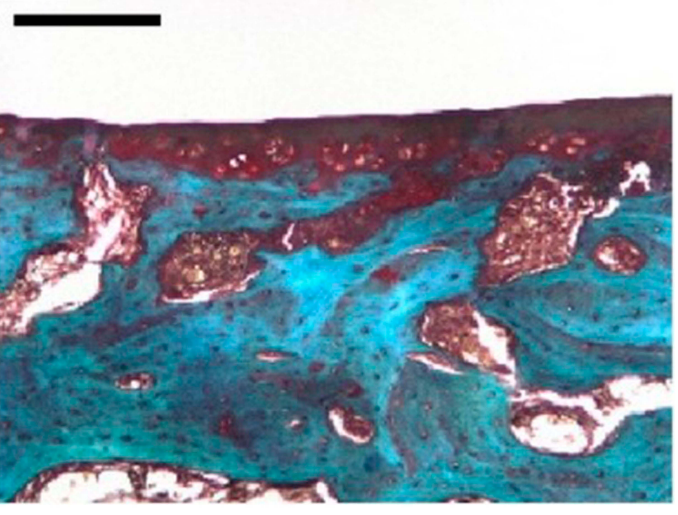

$(100 x)$

Figure 4 BMP-7 loaded PLGA nanoparticles incorporated with the fibrous PLGA scaffolds for cartilage repair. (A) Schematic illustration demonstrated release BMP-7 from nanoparticles on the PLGA scaffolds. (B) The release kinetic of BMP-7 was measured over 2 weeks. (C) H\&E staining demonstrated that PLGA/MSC/BMP-7 group resulted in a thick hyaline cartilage restoration. (D) Safranin-O staining supported PLGA/MSC/BMP-7 group with an obvious GAG deposition. Scale bar: $500 \mu$ m.

Notes: Reprinted from Kim HJ, Han MA, Shin JY, et al. Intra-articular delivery of synovium-resident mesenchymal stem cells via BMP-7-loaded fibrous PLGA scaffolds for cartilage repair. J Control Release. 2019;302:169-180. Copyright (2019), with permission from Elsevier. ${ }^{106}$

bioactive scaffolds with controlled-release function in cartilage tissue engineering. ${ }^{112}$

\section{Conclusion and Future Outlook}

The current clinical approaches achieved limited success in articular cartilage defects. However, the advent of tissue engineering promises to overcome the shortcomings of current clinical treatments of cartilage injury. Significant progress has been made for the optimization of scaffold design and the basic biology of growth factor manipulation. In a relatively short span, various polymer scaffoldbased controlled release systems have been successfully developed for controlled delivery of growth factors to promote cartilage regeneration. Additionally, multiple growth factor delivery in a simultaneous or spatiotemporal manner based on polymer scaffolds for cartilage tissue engineering has become a popular area of research.
While polymer scaffold-based growth factor delivery systems are logical and appealing, cost-effectiveness and safety issues are guiding the research to develop optimal delivery systems that allow dose reduction and precise localization. In addition, there remain several biological and engineering challenges that should be taken into account. First, there is no standard qualitative and quantitative procedure for evaluating release systems, and the regeneration assessment is mostly based on animal models. Thus, the release kinetics and bioactivity of growth factors from the delivery system in humans needs extensive clinical validation. Second, for most defect model studies, the actual dosage of growth factors released in vivo lacked clear evidence. It is necessary to create some reliable assessment tools that noninvasively track the growth factor delivery system after implantation. In addition, multiple growth factor delivery may not result 
in synergistic effects, and certain growth factors only exert bioactivities in a specific scaffold environment. Therefore, studies in the future should thoroughly verify the interactions that should be important to obtain the benefits that can be achieved from the association of scaffolds and growth factors.

\section{Acknowledgments}

This work was supported by the National Natural Science Foundation of China (Grant No. 31870961, 81501879), the Sino-German Center for Research Promotion (Grant No. GZ1219), the International Cooperation Project of the Science and Technology Department of Sichuan Province (Grant No. 2015HH0049), and the National Clinical Research Center for Geriatrics, West China Hospital, Sichuan University (Grant No. Z2018A11). We would like to thank Enago for editing the language.

\section{Disclosure}

The authors report no conflicts of interest in this work.

\section{References}

1. Carballo CB, Nakagawa Y, Sekiya I, Rodeo SA. Basic science of articular cartilage. Clin Sports Med. 2017;36(3):413-425. doi:10.1016/j.csm.2017.02.001

2. Camarero-Espinosa S, Rothen-Rutishauser B, Foster EJ, Weder C. Articular cartilage: from formation to tissue engineering. Biomater Sci. 2016;4(5):734-767. doi:10.1039/C6BM00068A

3. Roseti L, Desando G, Cavallo C, Petretta M, Grigolo B. Articular cartilage regeneration in osteoarthritis. Cells. 2019;8(11):1305. doi: $10.3390 /$ cells 8111305

4. Nasiri N, Hosseini S, Alini M, Khademhosseini A, Baghaban Eslaminejad M. Targeted cell delivery for articular cartilage regeneration and osteoarthritis treatment. Drug Discov Today. 2019;24 (11):2212-2224. doi:10.1016/j.drudis.2019.07.010

5. Disease GBD, Injury I, Prevalence C. Global, regional, and national incidence, prevalence, and years lived with disability for 328 diseases and injuries for 195 countries, 1990-2016: a systematic analysis for the Global Burden of Disease Study 2016. Lancet. 2017;390(10100):1211-1259. doi:10.1016/S0140-6736(17)32154-2

6. Cucchiarini M, Madry H. Biomaterial-guided delivery of gene vectors for targeted articular cartilage repair. Nat Rev Rheumatol. 2019;15(1):18-29. doi:10.1038/s41584-018-0125-2

7. Lamplot JD, Schafer KA, Matava MJ. Treatment of failed articular cartilage reconstructive procedures of the knee: a systematic review. Orthop J Sports Med. 2018;6(3):2325967118761871.

8. Salzmann GM, Niemeyer P, Hochrein A, Stoddart MJ, Angele P. Articular cartilage repair of the knee in children and adolescents. Orthop J Sports Med. 2018;6(3):2325967118760190. doi:10.1177/ 2325967118760190

9. Kwon H, Brown WE, Lee CA, et al. Surgical and tissue engineering strategies for articular cartilage and meniscus repair. Nat Rev Rheumatol. 2019;15(9):550-570. doi:10.1038/s41584-019-0255-1

10. Medvedeva EV, Grebenik EA, Gornostaeva SN, et al. Repair of damaged articular cartilage: current approaches and future directions. Int J Mol Sci. 2018;19(8):2366. doi:10.3390/ijms19082366
11. Vazquez-Portalati NN, Kilmer CE, Panitch A, Liu JC. Characterization of collagen type $\mathrm{i}$ and ii blended hydrogels for articular cartilage tissue engineering. Biomacromolecules. 2016;17 (10):3145-3152. doi:10.1021/acs.biomac.6b00684

12. Huang HJ, Tsai YL, Lin SH, Hsu SH. Smart polymers for cell therapy and precision medicine. J Biomed Sci. 2019;26(1):73. doi:10.1186/s12929-019-0571-4

13. Sivadas VP, Dhawan S, Babu J, Haridas V, Nair PD. Glutamic acid-based dendritic peptides for scaffold-free cartilage tissue engineering. Acta Biomater. 2019;99:196-210. doi:10.1016/j. actbio.2019.09.010

14. Li Y, Liu Y, Xun X, Zhang W, Xu Y, Gu D. Three-dimensional porous scaffolds with biomimetic microarchitecture and bioactivity for cartilage tissue engineering. ACS Appl Mater Interfaces. 2019;11(40):36359-36370. doi:10.1021/acsami.9b12206

15. Rogan $H$, Ilagan $F$, Tong $X$, Chu CR, Yang F. Microribbonhydrogel composite scaffold accelerates cartilage regeneration in vivo with enhanced mechanical properties using mixed stem cells and chondrocytes. Biomaterials. 2020;228:119579. doi:10.1016/j.biomaterials.2019.119579

16. Iturriaga L, Hernaez-Moya R, Erezuma I, Dolatshahi-Pirouz A, Orive G. Advances in stem cell therapy for cartilage regeneration in osteoarthritis. Expert Opin Biol Ther. 2018;18(8):883-896. doi:10.1080/14712598.2018.1502266

17. Goldstein JM, Tabebordbar M, Zhu K, et al. In situ modification of tissue stem and progenitor cell genomes. Cell Rep. 2019;27 (4):1254-1264 e1257. doi:10.1016/j.celrep.2019.03.105

18. Mitchell AC, Briquez PS, Hubbell JA, Cochran JR. Engineering growth factors for regenerative medicine applications. Acta Biomater. 2016;30:1-12. doi:10.1016/j.actbio.2015.11.007

19. Caballero Aguilar LM, Silva SM, Moulton SE. Growth factor delivery: defining the next generation platforms for tissue engineering. $J$ Control Release. 2019;306:40-58. doi:10.1016/j.jconrel.2019.05.028

20. Subbiah R, Guldberg RE. Materials science and design principles of growth factor delivery systems in tissue engineering and regenerative medicine. Adv Healthc Mater. 2019;8(1):e1801000. doi:10.1002/adhm.201801000

21. Patel DK, Lim KT. Biomimetic polymer-based engineered scaffolds for improved stem cell function. Materials. 2019;12(18). doi:10.3390/ma12182950

22. Boni R, Ali A, Shavandi A, Clarkson AN. Current and novel polymeric biomaterials for neural tissue engineering. $J$ Biomed Sci. 2018;25(1):90. doi:10.1186/s12929-018-0491-8

23. Uz U, Gunhan K, Vatansever S, Kivanc M, Yuceturk AV. Novel simple strategy for cartilage tissue engineering using stem cells and synthetic polymer scaffold. J Craniofac Surg. 2019;30(3):940-943. doi: 10.1097/SCS.0000000000005374

24. Sensharma P, Madhumathi G, Jayant RD, Jaiswal AK. Biomaterials and cells for neural tissue engineering: current choices. Mater Sci Eng C Mater Biol Appl. 2017;77:1302-1315. doi:10.1016/j. msec.2017.03.264

25. Asadian M, Chan KV, Norouzi M, et al. Fabrication and plasma modification of nanofibrous tissue engineering scaffolds. Nanomaterials. 2020;10(1):119. doi:10.3390/nano10010119

26. Eftekhari A, Maleki Dizaj S, Sharifi S, et al. The use of nanomaterials in tissue engineering for cartilage regeneration; current approaches and future perspectives. Int J Mol Sci. 2020;21 (2):536. doi:10.3390/ijms21020536

27. Gupte MJ, Swanson WB, Hu J, et al. Pore size directs bone marrow stromal cell fate and tissue regeneration in nanofibrous macroporous scaffolds by mediating vascularization. Acta Biomater. 2018;82:1-11. doi:10.1016/j.actbio.2018.10.016

28. Liu Q, Wang J, Chen Y, et al. Suppressing mesenchymal stem cell hypertrophy and endochondral ossification in 3D cartilage regeneration with nanofibrous poly(l-lactic acid) scaffold and matrilin-3. Acta Biomater. 2018;76:29-38. doi:10.1016/j.actbio.2018.06.027 
29. Hu J, Feng K, Liu X, Ma PX. Chondrogenic and osteogenic differentiations of human bone marrow-derived mesenchymal stem cells on a nanofibrous scaffold with designed pore network. Biomaterials. 2009;30(28):5061-5067. doi:10.1016/j.biomaterials.2009.06.013

30. Perona R. Cell signalling: growth factors and tyrosine kinase receptors. Clin Transl Oncol. 2006;8(2):77-82. doi:10.1007/ s12094-006-0162-1

31. Horbelt D, Denkis A, Knaus P. A portrait of transforming growth factor $\beta$ superfamily signalling: background matters. Int J Biochem Cell Biol. 2012;44(3):469-474. doi:10.1016/j.biocel.2011.12.013

32. Madry H, Rey-Rico A, Venkatesan JK, Johnstone B, Cucchiarini M. Transforming growth factor beta-releasing scaffolds for cartilage tissue engineering. Tissue Eng Part B Rev. 2014;20 (2):106-125. doi:10.1089/ten.teb.2013.0271

33. Coricor G, Serra R. TGF- $\beta$ regulates phosphorylation and stabilization of Sox 9 protein in chondrocytes through p38 and Smad dependent mechanisms. Sci Rep. 2016;6(1):38616. doi:10.1038/srep38616

34. Derynck R, Zhang YE. Smad-dependent and Smad-independent pathways in TGF- $\beta$ family signalling. Nature. 2003;425 (6958):577-584. doi:10.1038/nature02006

35. Kim IG, Ko J, Lee HR, Do SH, Park K. Mesenchymal cells condensation-inducible mesh scaffolds for cartilage tissue engineering. Biomaterials. 2016;85:18-29. doi:10.1016/j.biomaterials. 2016.01.048

36. Richter W. Mesenchymal stem cells and cartilage in situ regeneration. J Intern Med. 2009;266(4):390-405. doi:10.1111/ j.1365-2796.2009.02153.x

37. Patil AS, Sable RB, Kothari RM. An update on transforming growth factor- $\beta$ (TGF- $\beta$ ): sources, types, functions and clinical applicability for cartilage/bone healing. J Cell Physiol. 2011;226 (12):3094-3103. doi:10.1002/jcp.22698

38. Ying J, Wang $\mathrm{P}$, Zhang $\mathrm{S}$, et al. Transforming growth factor-beta1 promotes articular cartilage repair through canonical Smad and hippo pathways in bone mesenchymal stem cells. Life Sci. 2018;192:84-90. doi:10.1016/j.1fs.2017.11.028

39. Maruki H, Sato M, Takezawa T, et al. Effects of a cell-free method using collagen vitrigel incorporating TGF-beta1 on articular cartilage repair in a rabbit osteochondral defect model. J Biomed Mater Res B Appl Biomater. 2017;105(8):2592-2602. doi:10.1002/jbm. b.33792

40. Kopesky PW, Vanderploeg EJ, Kisiday JD, Frisbie DD, Sandy JD, Grodzinsky AJ. Controlled delivery of transforming growth factor betal by self-assembling peptide hydrogels induces chondrogenesis of bone marrow stromal cells and modulates Smad2/3 signaling. Tissue Eng Part A. 2011;17(1-2):83-92. doi:10.1089/ten.tea. 2010.0198

41. Guo X, Park H, Young S, et al. Repair of osteochondral defects with biodegradable hydrogel composites encapsulating marrow mesenchymal stem cells in a rabbit model. Acta Biomater. 2010;6 (1):39-47. doi:10.1016/j.actbio.2009.07.041

42. Bakker AC, van de Loo FA, van Beuningen HM, et al. Overexpression of active TGF-beta-1 in the murine knee joint: evidence for synovial-layerdependent chondro-osteophyte formation. Osteoarthritis Cartilage. 2001;9(2):128-136. doi:10.1053/joca.2000.0368

43. Meng XM, Nikolic-Paterson DJ, Lan HY. TGF-beta: the master regulator of fibrosis. Nat Rev Nephrol. 2016;12(6):325-338. doi:10.1038/nrneph.2016.48

44. van Beuningen HM, Glansbeek HL, van der Kraan PM, van den Berg WB. Osteoarthritis-like changes in the murine knee joint resulting from intra-articular transforming growth factor-beta injections. Osteoarthritis Cartilage. 2000;8(1):25-33. doi:10.1053/ joca. 1999.0267

45. Gomez-Puerto MC, Iyengar PV, Garcia de Vinuesa A, Ten Dijke P, Sanchez-Duffhues G. Bone morphogenetic protein receptor signal transduction in human disease. J Pathol. 2019;247(1):9-20. doi:10.1002/path.5170
46. Mulloy B, Rider CC. The bone morphogenetic proteins and their antagonists. Vitam Horm. 2015;99:63-90.

47. Retting KN, Song B, Yoon BS, Lyons KM. BMP canonical Smad signaling through Smad1 and Smad5 is required for endochondral bone formation. Development. 2009;136(7):1093-1104. doi:10.1242/dev.029926

48. Deng ZH, Li YS, Gao X, Lei GH, Huard J. Bone morphogenetic proteins for articular cartilage regeneration. Osteoarthritis Cartilage. 2018;26(9):1153-1161. doi:10.1016/j.joca.2018.03.007

49. Vayas R, Reyes R, Rodriguez-Evora M, Del Rosario C, Delgado A, Evora C. Evaluation of the effectiveness of a bMSC and BMP-2 polymeric trilayer system in cartilage repair. Biomed Mater. 2017;12(4):045001. doi:10.1088/1748-605X/aa6f1c

50. Yang HS, La WG, Bhang SH, et al. Hyaline cartilage regeneration by combined therapy of microfracture and long-term bone morphogenetic protein-2 delivery. Tissue Eng Part A. 2011;17(13-14):1809-1818. doi:10.1089/ten.tea.2010.0540

51. Sekiya I, Larson BL, Vuoristo JT, Reger RL, Prockop DJ. Comparison of effect of BMP-2, -4 , and -6 on in vitro cartilage formation of human adult stem cells from bone marrow stroma. Cell Tissue Res. 2005;320(2):269-276. doi:10.1007/s00441-004-1075-3

52. Lopiz-Morales $\mathrm{Y}$, Abarrategi $\mathrm{A}$, Ramos $\mathrm{V}$, et al. In vivo comparison of the effects of rhBMP-2 and rhBMP-4 in osteochondral tissue regeneration. Eur Cell Mater. 2010;20:367-378. doi:10.22203/ eCM.v020a30

53. Ramirez DM, Ramirez MR, Reginato AM, Medici D. Molecular and cellular mechanisms of heterotopic ossification. Histol Histopathol. 2014;29(10):1281-1285. doi:10.14670/HH-29.1281

54. Wang X, Li F, Xie L, et al. Inhibition of overactive TGF-beta attenuates progression of heterotopic ossification in mice. Nat Commun. 2018;9(1):551. doi:10.1038/s41467-018-02988-5

55. Liebesny PH, Mroszczyk K, Zlotnick H, et al. Enzyme pretreatment plus locally delivered HB-IGF-1 stimulate integrative cartilage repair in vitro. Tissue Eng Part A. 2019;25(17-18):1191-1201. doi:10.1089/ten.tea.2019.0013

56. Zhou Q, Li B, Zhao J, Pan W, Xu J, Chen S. IGF-I induces adipose derived mesenchymal cell chondrogenic differentiation in vitro and enhances chondrogenesis in vivo. Cell Dev Biol Anim. 2016;52 (3):356-364. doi:10.1007/s11626-015-9969-9

57. An C, Cheng Y, Yuan Q, Li J. IGF-1 and BMP-2 induces differentiation of adipose-derived mesenchymal stem cells into chondrocytes-like cells. Ann Biomed Eng. 2010;38(4):1647-1654. doi:10.1007/s10439-009-9892-x

58. Danisovic L, Varga I, Polak S. Growth factors and chondrogenic differentiation of mesenchymal stem cells. Tissue Cell. 2012;44 (2):69-73. doi:10.1016/j.tice.2011.11.005

59. Gugjoo MB, Abdelbaset-Ismail A, Abdelbaset-Ismail A, et al. Mesenchymal stem cells with IGF-1 and TGF- $\beta 1$ in laminin gel for osteochondral defects in rabbits. Biomed Pharmacother. 2017;93:1165-1174. doi:10.1016/j.biopha.2017.07.032

60. Lu S, Lam J, Trachtenberg JE, et al. Dual growth factor delivery from bilayered, biodegradable hydrogel composites for spatially-guided osteochondral tissue repair. Biomaterials. 2014;35 (31):8829-8839. doi:10.1016/j.biomaterials.2014.07.006

61. Holland TA, Bodde EW, Cuijpers VM, et al. Degradable hydrogel scaffolds for in vivo delivery of single and dual growth factors in cartilage repair. Osteoarthritis Cartilage. 2007;15(2):187-197. doi:10.1016/j.joca.2006.07.006

62. Martin I, Vunjak-Novakovic G, Yang J, Langer R, Freed LE. Mammalian chondrocytes expanded in the presence of fibroblast growth factor 2 maintain the ability to differentiate and regenerate three-dimensional cartilaginous tissue. Exp Cell Res. 1999;253 (2):681-688. doi:10.1006/excr.1999.4708

63. Correa D, Somoza RA, Lin P, et al. Sequential exposure to fibroblast growth factors (FGF) 2, 9 and 18 enhances hMSC chondrogenic differentiation. Osteoarthritis Cartilage. 2015;23(3):443-453. doi:10. 1016/j.joca.2014.11.013 
64. Solchaga LA, Penick K, Goldberg VM, Caplan AI, Welter JF. Fibroblast growth factor-2 enhances proliferation and delays loss of chondrogenic potential in human adult bone-marrow-derived mesenchymal stem cells. Tissue Eng Part A. 2010;16(3):1009-1019. doi:10.1089/ten.tea.2009.0100

65. Ishii I, Mizuta H, Sei A, Hirose J, Kudo S, Hiraki Y. Healing of full-thickness defects of the articular cartilage in rabbits using fibroblast growth factor-2 and a fibrin sealant. $J$ Bone Joint Surg Br. 2007;89-B(5):693-700. doi:10.1302/0301-620X.89B5.18450

66. Hildner F, Peterbauer A, Wolbank S, et al. FGF-2 abolishes the chondrogenic effect of combined BMP-6 and TGF-beta in human adipose derived stem cells. J Biomed Mater Res A. 2010;94 (3):978-987. doi:10.1002/jbm.a.32761

67. Lee JW, Kim YH, Kim SH, Han SH, Hahn SB. Chondrogenic differentiation of mesenchymal stem cells and its clinical applications. Yonsei Med J. 2004;45(Suppl):41-47. doi:10.3349/ ymj.2004.45.Suppl.41

68. Kieswetter K, Schwartz Z, Alderete M, Dean DD, Boyan BD. Platelet derived growth factor stimulates chondrocyte proliferation but prevents endochondral maturation. Endocrine. 1997;6 (3):257-264. doi:10.1007/BF02820501

69. Yuan L-J, Niu -C-C, Lin -S-S, et al. Additive effects of hyperbaric oxygen and platelet-derived growth factor-BB in chondrocyte transplantation via up-regulation expression of platelet-derived growth factor- $\beta$ receptor. $J$ Orthop Res. 2009;27(11):1439-1446. doi: $10.1002 /$ jor.20889

70. Sarban S, Tabur H, Baba ZF, Isikan UE. The positive impact of platelet-derived growth factor on the repair of full-thickness defects of articular cartilage. Eklem Hastalik Cerrahisi. 2019;30(2):91-96. doi:10.5606/ehc.2019.64018

71. Zhao GZ, Zhang LQ, Liu Y, et al. Effects of platelet-derived growth factor on chondrocyte proliferation, migration and apoptosis via regulation of GIT1 expression. Mol Med Rep. 2016;14 (1):897-903. doi:10.3892/mmr.2016.5291

72. Schmidt MB, Chen EH, Lynch SE. A review of the effects of insulin-like growth factor and platelet derived growth factor on in vivo cartilage healing and repair. Osteoarthritis Cartilage. 2006;14(5):403-412. doi:10.1016/j.joca.2005.10.011

73. Gaissmaier C, Fritz J, Krackhardt T, Flesch I, Aicher WK, Ashammakhi N. Effect of human platelet supernatant on proliferation and matrix synthesis of human articular chondrocytes in monolayer and three-dimensional alginate cultures. Biomaterials. 2005;26(14):1953-1960. doi:10.1016/j.biomaterials.2004.06.031

74. Kim YS, Park DY, Cho YH, et al. Cultured chondrocyte and porcine cartilage-derived substance (PCS) construct as a possible dorsal augmentation material in rhinoplasty: a preliminary animal study. J Plast Reconstr Aesthet Surg. 2015;68(5):659-666. doi:10.1016/j.bjps.2014.12.017

75. Maehara H, Sotome S, Yoshii T, et al. Repair of large osteochondral defects in rabbits using porous hydroxyapatite/collagen (HAp/ Col) and fibroblast growth factor-2 (FGF-2). J Orthop Res. 2010;28 (5):677-686. doi:10.1002/jor.21032

76. Wang W, Li B, Yang J, et al. The restoration of full-thickness cartilage defects with BMSCs and TGF-beta 1 loaded PLGA/fibrin gel constructs. Biomaterials. 2010;31(34):8964-8973. doi:10.1016/ j.biomaterials.2010.08.018

77. Re'em T, Kaminer-Israeli $\mathrm{Y}$, Ruvinov $\mathrm{E}$, Cohen $\mathrm{S}$. Chondrogenesis of hMSC in affinity-bound TGF-beta scaffolds. Biomaterials. 2012;33(3):751-761. doi:10.1016/j.biomaterials. 2011.10.007

78. Aksel H, Ozturk S, Serper A, Ulubayram K. VEGF/BMP-2 loaded three-dimensional model for enhanced angiogenic and odontogenic potential of dental pulp stem cells. Int Endod J. 2018;51 (4):420-430. doi:10.1111/iej.12869
79. Lee K, Silva EA, Mooney DJ. Growth factor delivery-based tissue engineering: general approaches and a review of recent developments. $J R$ Soc Interface. 2011;8(55):153-170. doi:10. 1098/rsif.2010.0223

80. Chen Y, Wu T, Huang S, et al. Sustained release SDF-1alpha/TGFbeta1-loaded silk fibroin-porous gelatin scaffold promotes cartilage repair. ACS Appl Mater Interfaces. 2019;11(16):14608-14618. doi:10.1021/acsami.9b01532

81. Tang X, Muhammad H, McLean C, et al. Connective tissue growth factor contributes to joint homeostasis and osteoarthritis severity by controlling the matrix sequestration and activation of latent TGF $\beta$. Ann Rheum Dis. 2018;77(9):1372-1380. doi:10.1136/annrheumdis2018-212964

82. Fan H, Tao H, Wu Y, Hu Y, Yan Y, Luo Z. TGF-beta3 immobilized PLGA-gelatin/chondroitin sulfate/hyaluronic acid hybrid scaffold for cartilage regeneration. J Biomed Mater Res A. 2010;95 (4):982-992. doi:10.1002/jbm.a.32899

83. Lee H, Lim S, Birajdar MS, Lee SH, Park H. Fabrication of FGF-2 immobilized electrospun gelatin nanofibers for tissue engineering. Int J Biol Macromol. 2016;93(Pt B):1559-1566. doi:10.1016/j. ijbiomac.2016.07.041

84. Zhang Z, Gupte MJ, Jin X, Ma PX. Injectable peptide decorated functional nanofibrous hollow microspheres to direct stem cell differentiation and tissue regeneration. Adv Funct Mater. 2015;25 (3):350-360. doi:10.1002/adfm.201402618

85. Sheridan MH, Shea LD, Peters MC, Mooney DJ. Bioabsorbable polymer scaffolds for tissue engineering capable of sustained growth factor delivery. J Control Release. 2000;64(1-3):91-102. doi:10.1016/S0168-3659(99)00138-8

86. Manavitehrani I, Le TYL, Daly S, et al. Formation of porous biodegradable scaffolds based on poly(propylene carbonate) using gas foaming technology. Mater Sci Eng C Mater Biol Appl. 2019;96:824-830. doi:10.1016/j.msec.2018.11.088

87. Dang M, Saunders L, Niu X, Fan Y, Ma PX. Biomimetic delivery of signals for bone tissue engineering. Bone Res. 2018;6:25. doi:10.1038/s41413-018-0025-8

88. Patel JM, Saleh KS, Burdick JA, Mauck RL. Bioactive factors for cartilage repair and regeneration: improving delivery, retention, and activity. Acta Biomater. 2019;93:222-238. doi:10.1016/j.actbio. 2019.01.061

89. Filova E, Rampichova M, Litvinec A, et al. A cell-free nanofiber composite scaffold regenerated osteochondral defects in miniature pigs. Int J Pharm. 2013;447(1-2):139-149. doi:10.1016/j.ijpharm. 2013.02.056

90. Cheng R, Liu L, Xiang Y, et al. Advanced liposome-loaded scaffolds for therapeutic and tissue engineering applications. Biomaterials. 2020;232:119706. doi:10.1016/j.biomaterials.2019. 119706

91. Santo VE, Gomes ME, Mano JF, Reis RL. Controlled release strategies for bone, cartilage, and osteochondral engineering-part I: recapitulation of native tissue healing and variables for the design of delivery systems. Tissue Eng Part B Rev. 2013;19(4):308-326. doi: $10.1089 /$ ten.teb. 2012.0138

92. Lam J, Lu S, Kasper FK, Mikos AG. Strategies for controlled delivery of biologics for cartilage repair. Adv Drug Deliv Rev. 2015;84:123-134. doi:10.1016/j.addr.2014.06.006

93. Willerth SM. How can microsphere-mediated delivery of small molecules serve as a novel tool for engineering tissues from stem cells? Ther Deliv. 2019;10(11):671-674. doi:10.4155/tde-20190071

94. Gupta V, Khan Y, Berkland CJ, Laurencin CT, Detamore MS. Microsphere-based scaffolds in regenerative engineering. Annu Rev Biomed Eng. 2017;19:135-161. doi:10.1146/annurev-bioeng $-071516-044712$ 
95. He Q, Zhang J, Liao Y, et al. Current advances in microsphere based cell culture and tissue engineering. Biotechnol Adv. 2019;107459.

96. Kudva AK, Dikina AD, Luyten FP, Alsberg E, Patterson J. Gelatin microspheres releasing transforming growth factor drive in vitro chondrogenesis of human periosteum derived cells in micromass culture. Acta Biomater. 2019;90:287-299. doi:10.1016/j.actbio. 2019.03.039

97. Wang J, Wang Y, Sun X, et al. Biomimetic cartilage scaffold with orientated porous structure of two factors for cartilage repair of knee osteoarthritis. Artif Cells Nanomed Biotechnol. 2019;47 (1):1710-1721. doi:10.1080/21691401.2019.1607866

98. Min Q, Liu J, Li J, Wan Y, Wu J. Chitosan-polylactide/hyaluronic acid complex microspheres as carriers for controlled release of bioactive transforming growth Factor- $\beta 1$. Pharmaceutics. 2018;10 (4):239. doi:10.3390/pharmaceutics10040239

99. Wang J, Sun X, Zhang Z, et al. Silk fibroin/collagen/hyaluronic acid scaffold incorporating pilose antler polypeptides microspheres for cartilage tissue engineering. Mater Sci Eng C Mater Biol Appl. 2019;94:35-44. doi:10.1016/j.msec.2018.09.017

100. Bian L, Zhai DY, Tous E, Rai R, Mauck RL, Burdick JA. Enhanced MSC chondrogenesis following delivery of TGF-beta3 from alginate microspheres within hyaluronic acid hydrogels in vitro and in vivo. Biomaterials. 2011;32(27):6425-6434. doi:10.1016/j.biomaterials. 2011.05.033

101. Makadia HK, Siegel SJ. Poly Lactic-co-Glycolic Acid (PLGA) as biodegradable controlled drug delivery carrier. Polymers. 2011;3 (3):1377-1397. doi:10.3390/polym3031377

102. Wang J, Yang Q, Cheng N, et al. Collagen/silk fibroin composite scaffold incorporated with PLGA microsphere for cartilage repair. Mater Sci Eng C Mater Biol Appl. 2016;61:705-711. doi:10.1016/j. msec.2015.12.097

103. DeFail AJ, Chu CR, Izzo N, Marra KG. Controlled release of bioactive TGF-beta 1 from microspheres embedded within biodegradable hydrogels. Biomaterials. 2006;27(8):1579-1585. doi:10. 1016/j.biomaterials.2005.08.013
104. Santo VE, Gomes ME, Mano JF, Reis RL. From nano- to macro-scale: nanotechnology approaches for spatially controlled delivery of bioactive factors for bone and cartilage engineering. Nanomedicine. 2012;7(7):1045-1066. doi:10.2217/nnm.12.78

105. Vrignaud S, Benoit JP, Saulnier P. Strategies for the nanoencapsulation of hydrophilic molecules in polymer-based nanoparticles. Biomaterials. 2011;32(33):8593-8604. doi:10.1016/j.biomaterials. 2011.07.057

106. Kim HJ, Han MA, Shin JY, et al. Intra-articular delivery of synovium-resident mesenchymal stem cells via BMP-7-loaded fibrous PLGA scaffolds for cartilage repair. J Control Release. 2019;302:169-180. doi:10.1016/j.jconrel.2019.04.002

107. Deepthi S, Jayakumar R. Prolonged release of TGF-beta from polyelectrolyte nanoparticle loaded macroporous chitin-poly(caprolactone) scaffold for chondrogenesis. Int J Biol Macromol. 2016;93(Pt B):1402-1409. doi:10.1016/j.ijbiomac.2016.03.068

108. Damanik FFR, Brunelli M, Pastorino L, et al. Sustained delivery of growth factors with high loading efficiency in a layer by layer assembly. Biomater Sci. 2019;8(1):174-188. doi:10.1039/C9BM0 0979E

109. De Koker S, Hoogenboom R, De Geest BG. Polymeric multilayer capsules for drug delivery. Chem Soc Rev. 2012;41(7):2867-2884. doi:10.1039/c2cs15296g

110. Yu X, Khalil A, Dang PN, Alsberg E, Murphy WL. Multilayered inorganic microparticles for tunable dual growth factor delivery. Adv Funct Mater. 2014;24(20):3082-3093. doi:10.1002/adfm. 201302859

111. Bittner SM, Guo JL, Mikos AG. Spatiotemporal control of growth factors in three-dimensional printed scaffolds. Bioprinting. 2018;12:e0032.

112. Hung KC, Tseng CS, Dai LG, Hsu SH. Water-based polyurethane 3D printed scaffolds with controlled release function for customized cartilage tissue engineering. Biomaterials. 2016;83:156-168. doi:10. 1016/j.biomaterials.2016.01.019
International Journal of Nanomedicine

\section{Publish your work in this journal}

The International Journal of Nanomedicine is an international, peerreviewed journal focusing on the application of nanotechnology in diagnostics, therapeutics, and drug delivery systems throughout the biomedical field. This journal is indexed on PubMed Central, MedLine, CAS, SciSearch ${ }^{\circledR}$, Current Contents ${ }^{\mathbb{R}} /$ Clinical Medicine,

\section{Dovepress}

Journal Citation Reports/Science Edition, EMBase, Scopus and the Elsevier Bibliographic databases. The manuscript management system is completely online and includes a very quick and fair peer-review

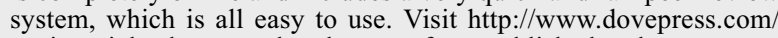
testimonials.php to read real quotes from published authors. 